\title{
вмJ Global Health The burden of misclassification of antepartum stillbirth in Nepal
} Rejina Gurung, ${ }^{1}$ Helena Litorp, ${ }^{2,3}$ Sara Berkelhamer, ${ }^{4}$ Hong Zhou, ${ }^{5}$
Bhim Singh Tinkari, ${ }^{6}$ Prajwal Paudel, ${ }^{6}$ Honey Malla, ${ }^{1}$ Srijana Sharma,
Ashish KC

\section{ABSTRACT}

Gurung R, Litorp Berkelhamer S, et al. The burden of misclassification of antepartum stillbirth in Nepal. BMJ Global Health 2019;4:e001936. doi:10.1136/ bmjgh-2019-001936

\section{Handling editor Sanni Yaya}

- Additional material is published online only. To view please visit the journal online (http://dx.doi.org/10.1136/ bmjgh-2019-001936).

Received 22 August 2019 Revised 27 October 2019 Accepted 2 November 2019

Check for updates

(c) Author(s) (or their employer(s)) 2019. Re-use permitted under CC BY-NC. No commercial re-use. See rights and permissions. Published by BMJ.

${ }^{1}$ Research, Golden Community, Lalitpur, Nepal

${ }^{2}$ Department of Global Health, Karolinska Institutet, Stockholm, Sweden

${ }^{3}$ Department of Women's and Children's Health, Uppsala

University, Uppsala, Sweden

${ }^{4}$ Department of Pediatrics, University at Buffalo, Buffalo, New York, United States ${ }^{5}$ Department of Maternal and Child Health, Peking University of Health Sciences, Peking, China

${ }^{6}$ Ministry of Health and Population, Kathmandu, Nepal

Correspondence to

Dr Ashish KC

aaashis7@yahoo.com to 5.76).
Background Globally, every year 1.1 million antepartum stillbirths occur with $98 \%$ of these deaths taking place in countries where the health system is poor. In this paper we examine the burden of misclassification of antepartum stillbirth in hospitals of Nepal and factors associated with misclassification.

Method A prospective observational study was conducted in 12 hospitals of Nepal for a period of 6 months. If fetal heart sounds (FHS) were detected at admission and during the intrapartum period, the antepartum stillbirth (fetal death $\geq 22$ weeks prior labour) recorded in patient's case note was recategorised as misclassified antepartum stillbirth. We further compared sociodemographic, obstetric and neonatal characteristics of misclassified and correctly classified antepartum stillbirths using bivariate and multivariate analysis.

Result A total of 41061 women were enrolled in the study and 39562 of the participants' FHS were taken at admission. Of the total participants whose FHS were taken at admission, 94.8\% had normal FHS, 4.7\% had abnormal FHS and $0.6 \%$ had no FHS at admission. Of the total 119 recorded antepartum stillbirths, 29 (24.4\%) had FHS at admission and during labour and therefore categorised as misclassified antepartum stillbirths. Multivariate analysis performed to adjust the risk of association revealed that complications during pregnancy resulted in a threefold risk of misclassification (adjusted 0R-3.35, 95\% Cl 1.95

Conclusion Almost 25\% of the recorded antepartum stillbirths were misclassified. Improving quality of data is crucial to improving accountability and quality of care. As the interventions to reduce antepartum stillbirth differ accurate measurement of antepartum stillbirth is critical. Trial registration number ISRCTN30829654.

\section{INTRODUCTION}

In 2015, an estimated 2.6 million stillbirths occurred worldwide, representing a $47.0 \%$ decrease from estimates of 4.0 million in $1990 .{ }^{1}$ Globally, data suggest that $49.1 \%$ of these stillbirths occur during the antepartum period, that is, before the start of the labour ${ }^{1}$ (antepartum stillbirth). Efforts to reduce the burden of antepartum stillbirths include high quality pregnancy care and management of

\section{Key questions}

What is already known?

- The trackers of Global Burden of Disease, WHO and International Health Metric and Evaluation, do not measure and monitor antepartum stillbirth, despite the fact that an estimated 1.1 million occur annually. Granular data on antepartum stillbirth is lacking.

- Examining the true burden of antepartum stillbirth is important to track quality of antenatal care.

What are the new findings?

- We used an algorithm of assess the misclassification of antepartum stillbirth in hospitals of Nepal.

- Almost one fourth of the antepartum stillbirths were found to be misclassified. Complications during pregnancy increased the risk of misclassification.

What do the new findings imply?

- As the interventions to reduce antepartum stillbirth differ, accurate measurement of antepartum stillbirth is critical.

- Poor recording of antepartum stillbirth in medica records is common and may reflect a devaluing of clinical records, misinterpretation of clinical data or misunderstanding of terminology or protecting themselves when complication have occurred during labour.

high-risk pregnancies, potentially including continuous monitoring in a hospital setting. In high income settings with quality intrapartum care, antepartum stillbirths estimate to account for ninety percent of the stillbirths. ${ }^{1}$ The average annual rate of reduction of stillbirths varies by region, countries and health system settings. ${ }^{2}$ The global annual rate of reduction of stillbirth was $1.9 \%$ between 1990 and 2015, a decline which was well behind rates of reduction of maternal or under-five mortality. ${ }^{1}$

To accelerate the reduction in stillbirths globally, the World Health Assembly in 2014 initiated Every Newborn Action Plan (ENAP). 194 countries committed to reduce stillbirth rates, with a target of 12 or less per 1000 births in all countries by $2030 .{ }^{34}$ Among the 


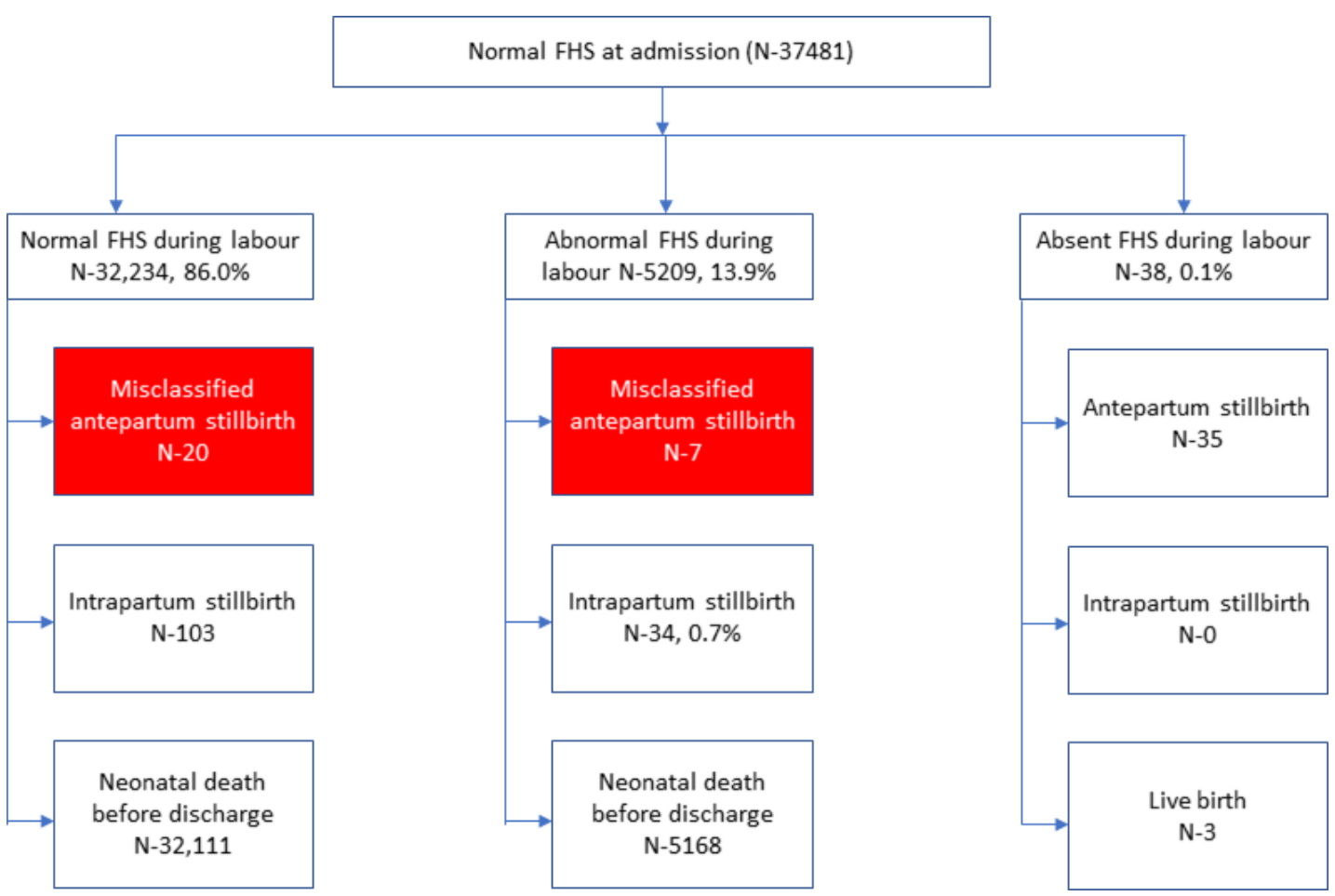

Figure 1 Birth outcome among babies who had normal fetalheart sounds (FHS) at admission.

five strategies placed forward to reduce and track deaths, improving data accountability was highlighted. ${ }^{3}$

The ENAP measurement improvement roadmap (2015-2020) outlined the tools to be developed to improve data accountability at each tier of the health system. ${ }^{5}$ The roadmap provided guidance to strengthen routine health information systems, crosslinking these data with civil registration and vital statistics (CRVS). ${ }^{5} \mathrm{~A}$ set of 10 core indicators was proposed to track the progress in birth outcome (maternal mortality ratio, stillbirth rate, neonatal mortality rate) as well as coverage of care (including skilled attendance at birth, early postnatal care, essential newborn care, antenatal corticosteroids, neonatal resuscitation, kangaroo mother care, treatment of severe neonatal infection) through the routine information system. ${ }^{5}$ The coverage of care indicators is currently being validated through a multicountry study. ${ }^{6}$ Measurement of stillbirth and neonatal mortality rates in CRVS, health survey and routine health information systems was designated as a priority action for change in the ENAP measurement roadmap. This action would require recording of stillbirths in the hospital register, tracking and compiling these data in the hospital periodic reports and reported them in the national Health Management Information System. The ENAP measurement roadmap did not outline reporting of antepartum stillbirths. Key data gaps have been identified in the process of estimating the global burden of stillbirth. Notably, countries that have highest burden of stillbirth have poor vital registration systems to track both stillbirth and neonatal deaths. ${ }^{7-9}$

Despite limitations of poor data measurement systems, there has been remarkable changes in healthcare seeking. ${ }^{10}$ The past two decades have seen a fourfold increase in rates of health facility delivery, resulting in more than two-thirds of deaths now occurring in these facilities. ${ }^{11}$ Improving documentation of these births and deaths will be key to evaluating progress in care and outcomes. ${ }^{712}$ In this paper, we examined the burden of misclassification of antepartum stillbirth in low resource healthcare settings in Nepal, and factors associated with misclassification.

\section{METHODS}

We performed a prospective observational study nested within a randomised control trial in 12 public hospitals of Nepal to evaluate the scaling up of a neonatal resuscitation Quality Improvement Cycle. ${ }^{13}$ For this study, we used data from the baseline period of 6 months (January to July 2017) prior to the implementation. The study has been reported as per the guidelines for Strengthening the Reporting of Observational Studies in Epidemiology. ${ }^{14} 15$

All 12 hospitals were referral level hospitals and provided Comprehensive Emergency Obstetric and Neonatal Care Services ${ }^{16} 17$ (parental antibiotics, parental uterotonic drugs, parenteral anticonvulsants for pre-eclampsia and eclampsia (ie, magnesium sulfate), manual removal of placenta, removal of retained products, assisted vaginal delivery, basic neonatal resuscitation, caesarean section and blood transfusion).

The hospitals had two different units for providing delivery and immediate newborn care service. In the labour unit, spontaneous and assisted vaginal delivery were attended by nurse-midwives. In these units, information on the delivery care and maternal and neonatal 


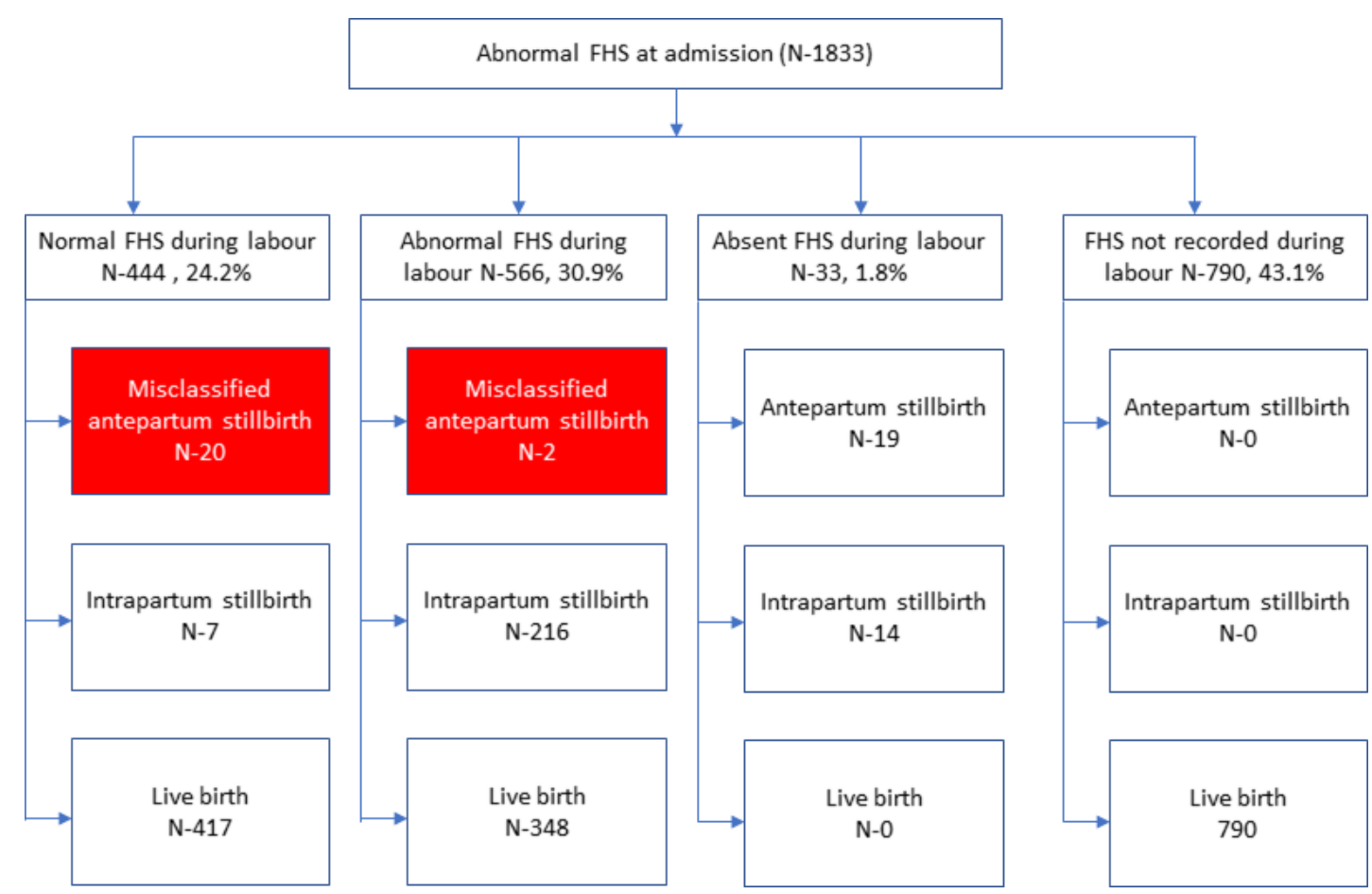

Figure 2 Birth outcome among babies who had abnormal fetalheart sounds (FHS) at admission.

outcomes were recorded in an obstetric register and medical records. The fetal heart rate monitoring was performed using stethoscope or pinard fetal heart rate monitor. Hospital standards included all pregnant women admitted in the hospital to have fetal heart sounds (FHS) checked at the time of admission and monitoring of FHS every half an hour during labour. In the operation theatre, caesarean sections were performed by obstetricians with resuscitation provided by medical doctors and nursing staff. Maternal and neonatal outcomes were recorded in the operation theatre register and medical records.

\section{Patient and public involvement}

This research question aims to assess the burden of misclassification was based on the patient's experience on stillbirth. The improved care and monitoring for high risk mother will reduce stillbirth. The results of the study will be disseminated to the study participants through local and national news media.

Eligibility criteria for enrolment included women with pregnancy of 22 weeks or more who were admitted in the hospital and consented to participation. Exclusion criteria women whose FHS was not measured at the time of admission.

\section{Data collection and management}

Independent data collectors were placed in each hospital throughout the study period to collect demographic, obstetric and neonatal information. A data quality coordinator was placed in each hospital to ensure the quality of data collection. The independent data collectors were trained on how to collect data and adhere to standard research protocol. The women who were admitted in the hospital were assessed by the health worker for eligibility to take part in the study. Informed consent was obtained for enrolment in the study. Interviews were conducted with women before discharge from the hospital to assess the demographic characteristics such as education and parity (online supplementary file 1). Extraction of the obstetric and neonatal data were completed from the patient case note after discharge from the hospital (online supplementary file 2). Data extraction sheets and interviews were reviewed by the coordinator daily to assure quality. At the end of each week, the filled forms were sealed in an opaque envelop and sent to central office in Kathmandu, Nepal. In the central office, the data entry officers reviewed each form for data completeness and coded the open-ended responses. The data entry officers then entered the data in the Census and Survey Processing System (CS-PRO) database. The data manager conducted weekly data cleaning in the CS-PRO database and transferred the data in SPSS V.23.0 each week in a secured server. After the completion of study, all data were extracted for data analysis.

For this study, the following variables of interest were extracted from the baseline database.

Obstetric complications during antepartum period ${ }^{18}$ Complications that a woman had during the intrapartum period including:

- Hypertensive disorder. classified by maternal diastolic blood pressure greater than or equal to $90 \mathrm{~mm} \mathrm{Hg}$ in two separate recordings.

- Antepartum haemorrhage: vaginal bleeding before onset of labour.

- Infection: clinical signs of infection.

- Multiple gestation-more than one pregnancy. 


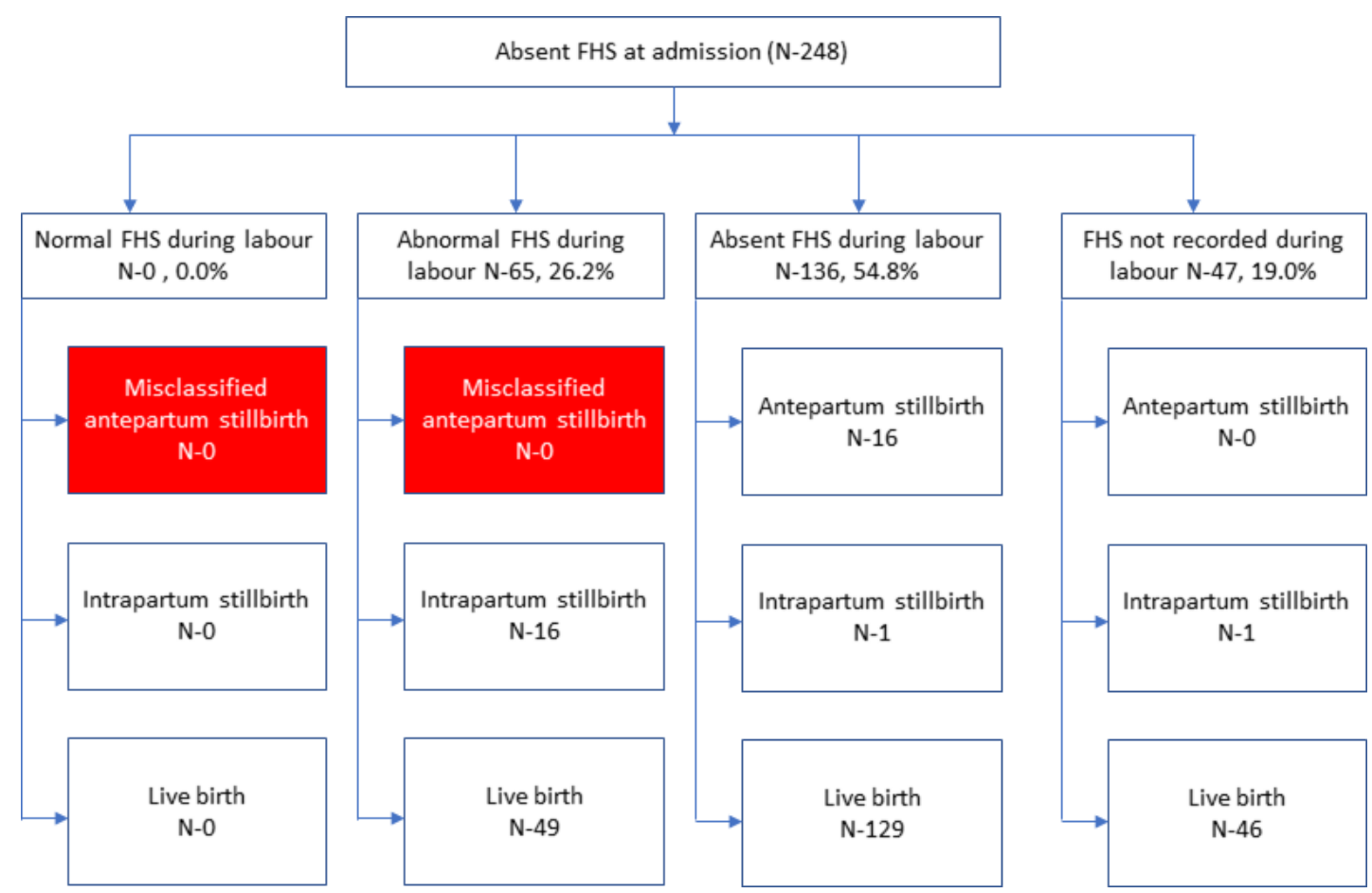

Figure 3 Birth outcome among women who had no fetalheart sounds (FHS) at admission.

FHS at admission: presence of FHS by auscultation at admission, categorised as normal $(>110$ and $<160$ beats per minute), abnormal ( $<110$ or $>160$ beats per minute), absent or not recorded.

FHS during labour: FHS during labour, categorised as normal ( $>110$ and $<160$ beats per minute), abnormal FHS $(<110$ or $>160$ beats per minute), absent or not recorded.

Gestational age: estimated from the last menstrual period in weeks. The variable was categorised into preterm $(<37$ weeks) and term ( $\geq 37$ weeks) gestation.

Birth weight: weight of the baby was taken on an analogue scale within 1 hour after birth. The variable was categorised into low birth weight $(<2500 \mathrm{~g})$ and normal birth weight ( $\geq 2500 \mathrm{~g})$.

\section{Birth outcome}

- Stillbirth: delivery of a fetus occurring after 22 weeks of gestation or with a birth weight more than $500 \mathrm{~g}$ that never breathed spontaneously after birth or after 10 min of resuscitation.

- True antepartum stillbirth: delivery of a fetus occurring after 22 weeks of gestation or with a birth weight more than $500 \mathrm{~g}$, who had no FHS at admission and no FHS present at labour. Since, absence of FHS at admission does not necessarily mean antepartum stillbirth, as the women might not be in labour. So, absence of FHS both at admission and during labour has been defined as antepartum stillbirth.

- Misclassified antepartum stillbirth: if the fetus was documented as an antepartum stillbirth in the patient case note who had FHS at admission and during labour, we categorised it as a misclassified antepartum stillbirth.

\section{Sociodemographic variables}

Mother's age was categorised as 15-19 years, 20-34 years and $\geq 35$ years. Maternal education was categorised as no education and primary education or more for those who had no formal education and formal education, respectively. Ethnicity was categorised as disadvantageous group (Dalit, Janjati and Muslim) and relatively advantageous group (Madhesi, Chettri/ Brahmin and other castes) based on hierarchical caste system of Nepal. ${ }^{19}$

\section{Data analysis}

Among cases documented as antenatal stillbirth in the patient case note, we analysed the presence of FHS at admission and FHS during labour. We built three different flow diagrams based on the FHS at admission, FHS during labour and birth outcome (figures 1-3). We compared the background characteristics (demographic, obstetric and neonatal) among misclassified antepartum stillbirths and true antepartum stillbirth. We assessed the risk factors for misclassification by comparing the obstetric characteristics (obstetric complication during antepartum period, gestational age, multiple gestation, birth weight) in the cohort of misclassified antepartum stillbirths with the cohort of true antepartum stillbirths. A Pearson $\chi^{2}$ test was utilised if the number of cases was more than five and Fischer's exact test if the number of cases was five or less. Obstetric characteristics which showed association were then considered for bivariate and multivariate logistic regression. Variables with more than $10 \%$ missing values were excluded from the analysis. 


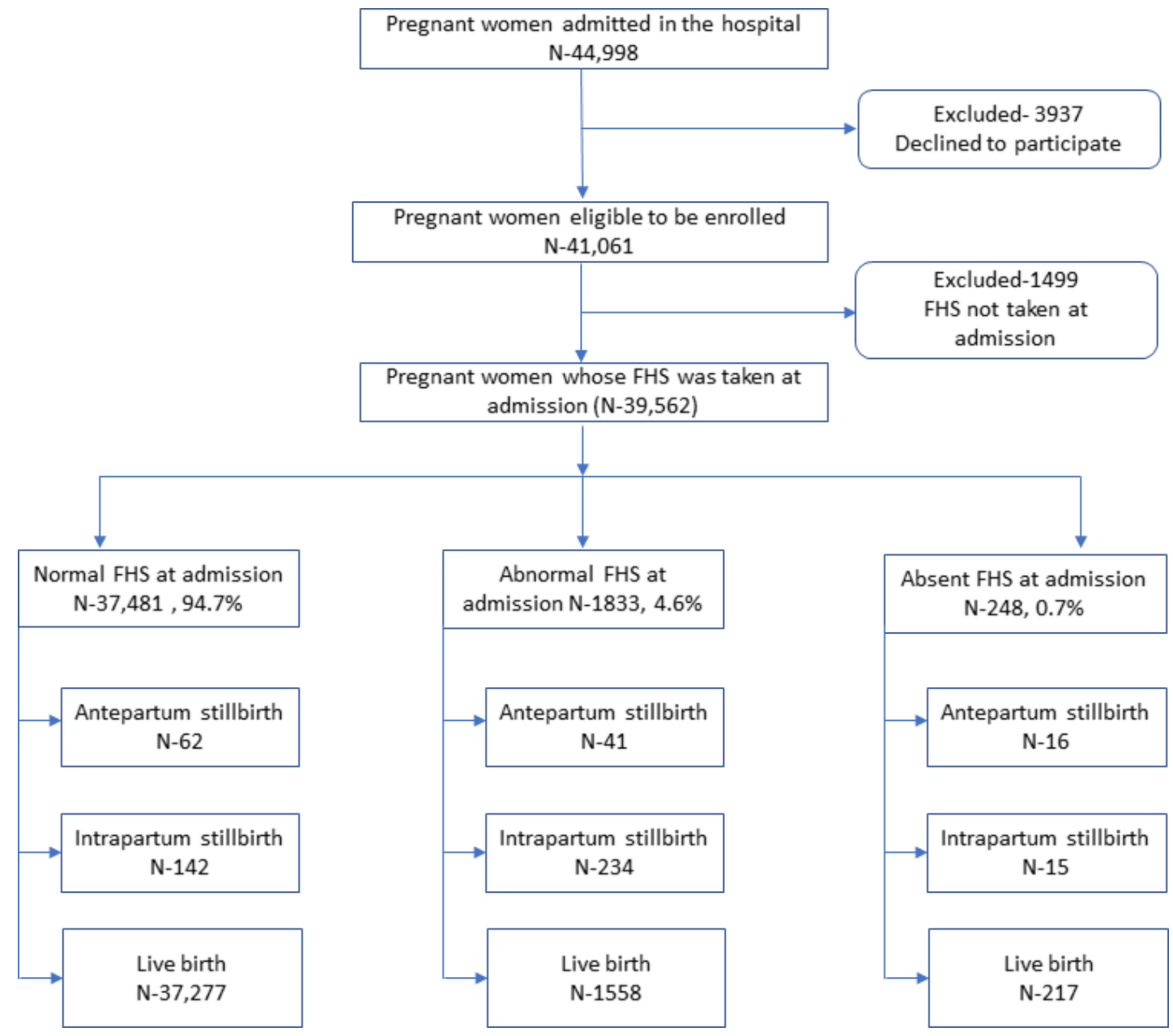

Figure 4 Participant flow figure. FHS, fetalheart sounds.

\section{RESULTS}

Among the 41061 women who were enrolled in the study, 39562 had FHS taken at admission. Of the total participants whose FHS was taken at admission, 37481 (94.8\%) had normal FHS, 1845 (4.7\%) had abnormal FHS and $233(0.6 \%)$ had no FHS at admission. Among the 37481 women who had normal FHS at admission, $62(0.2 \%)$ were diagnosed as antepartum stillbirth in the patient case note while 44 of the 1845 (2.2\%) women who had abnormal FHS at admission were diagnosed as antepartum stillbirth. Among the 233 women who had absent FHS at admission, only $16(6.9 \%)$ were diagnosed as antepartum stillbirth in the patient case note, with a total of 119 documented antenatal stillbirths in the cohort of 39562 (figure 4).

Among the women who had normal FHS at admission and normal FHS during labour (N-32 229), 20 of the birth were recorded antepartum stillbirth. Among the women who had normal FHS at admission and abnormal FHS during labour (N-5217), seven of the birth were recorded antepartum stillbirth (figure 1). Among the women who had abnormal FHS at admission and abnormal FHS during labour (N-558), two of the births were recorded as antepartum stillbirth (figure 2). Based on our operational definition of misclassified antepartum stillbirth, these 29 antepartum stillbirths who had FHS at admission and during labour was categorised as misclassified, which accounted $24.4 \%$ of the 119 recorded antepartum stillbirths (figures 1-3).

Among the remaining 90 recorded antepartum stillbirths, 35 of them had normal FHS at admission and absent FHS before birth (figure 1), 39 of them had abnormal FHS at admission and absent FHS during labour (figure 2) and 16 of them had absent FHS at admission and absent FHS during labour (figure 3). Based on the operational definition, these were categorised as correctly classified antepartum stillbirths.

We compared the sociodemographic, obstetric and neonatal characteristics between the misclassified (N-29) and correctly classified antepartum stillbirths (N-90). We found that complications during pregnancy were more common among misclassified antepartum stillbirth than true antepartum stillbirth (27.6\% vs $8.9 \%$, p value- 0.01$)$. The proportion of low birthweight babies were higher among the misclassified antepartum stillbirths than true antepartum stillbirth $(31.0 \%$ vs $11.1 \%$, $\mathrm{p}$ value- 0.01$)$. There was no difference in other sociodemographic (education and ethnicity), obstetric (parity, antenatal care (ANC) check-up and delivery preparation) and neonatal characteristics (preterm birth and sex) (table 1). 
Table 1 Background characteristics of misclassified and true antepartum stillbirth

\begin{tabular}{|c|c|c|c|c|}
\hline & $\begin{array}{l}\text { Misclassified antepartum } \\
\text { stillbirth (N-29) }\end{array}$ & $\begin{array}{l}\text { True antepartum } \\
\text { stillbirth (N-90) }\end{array}$ & Total (N-119) & $P$ value \\
\hline \multicolumn{5}{|l|}{ Formal education } \\
\hline Formal education & $1(3.4 \%)$ & $7(7.8 \%)$ & $8(6.7 \%)$ & \\
\hline No formal education & $28(96.6 \%)$ & $83(92.2 \%)$ & $111(93.3 \%)$ & $0.678^{*}$ \\
\hline \multicolumn{5}{|l|}{ Ethnicity } \\
\hline Advantaged group & $17(58.6 \%)$ & $38(42.2 \%)$ & $55(46.2 \%)$ & \\
\hline Disadvantaged group & $12(41.4 \%)$ & 52 (57.8\%) & 64 (53.8\%) & $0.123 \dagger$ \\
\hline \multicolumn{5}{|l|}{ Parity } \\
\hline Nullipara & $12(41.4 \%)$ & $37(41.1 \%)$ & $49(41.2 \%)$ & \\
\hline Primi & $5(17.2 \%)$ & $29(32.2 \%)$ & $34(28.6 \%)$ & \\
\hline Multipara & $12(41.4 \%)$ & $24(26.7 \%)$ & $36(30.3 \%)$ & \\
\hline \multicolumn{5}{|l|}{ Antenatal care (ANC) } \\
\hline At least one ANC & $1(3.4 \%)$ & $7(7.8 \%)$ & $8(6.7 \%)$ & \\
\hline No ANC & $28(96.6 \%)$ & $83(92.2 \%)$ & $111(93.3 \%)$ & $0.678^{*}$ \\
\hline \multicolumn{5}{|l|}{ Delivery preparations } \\
\hline Yes & $1(3.4 \%)$ & $7(7.8 \%)$ & $8(6.7 \%)$ & \\
\hline No & $28(96.6 \%)$ & $83(92.2 \%)$ & $111(93.3 \%)$ & $0.678^{\star}$ \\
\hline \multicolumn{5}{|c|}{ Complication during pregnancy } \\
\hline No & $21(72.4 \%)$ & $82(91.1 \%)$ & $103(86.6 \%)$ & \\
\hline Yes & $8(27.6 \%)$ & $8(8.9 \%)$ & $16(13.4 \%)$ & $0.01 \dagger$ \\
\hline \multicolumn{5}{|l|}{ Low birth weight } \\
\hline $2500 \mathrm{~g}$ or more & $20(69.0 \%)$ & $80(88.9 \%)$ & $100(84.0 \%)$ & \\
\hline Less than $2500 \mathrm{~g}$ & $9(31.0 \%)$ & $10(11.1 \%)$ & $19(16.0 \%)$ & $0.01 \dagger$ \\
\hline \multicolumn{5}{|l|}{ Preterm } \\
\hline 37 week or more & $22(75.9 \%)$ & 79 (87.8\%) & $101(84.9 \%)$ & \\
\hline Less than 37 weeks & $7(24.1 \%)$ & $11(12.2 \%)$ & $18(15.1 \%)$ & $0.119 \dagger$ \\
\hline \multicolumn{5}{|l|}{ Sex } \\
\hline Boy & $14(48.3 \%)$ & 44 (48.9\%) & 58 (48.7\%) & \\
\hline Girl & 15 (51.7\%) & 46 (51.1\%) & $61(51.3 \%)$ & $0.954 \dagger$ \\
\hline
\end{tabular}

*Fischer's exact test.

†Pearson's $\chi^{2}$ test.

We performed a multivariate analysis to adjust the risk of association between the complication during pregnancy and low birthweight babies. After the multivariate analysis, complication during pregnancy had threefoldrisk of misclassification (aOR-3.35, 95\% CI 1.95 to 5.76) but there was no significant association between low birth weight and misclassification (aOR-0.97, 95\% CI 0.59 to 1.60) (table 2).

\section{DISCUSSION}

Almost 25\% of recorded antepartum stillbirths in public hospitals in Nepal were misclassified antepartum stillbirth. The proportion of low birth weight was higher among the misclassified antepartum stillbirths compared with true antepartum stillbirths, but the association failed to meet significance in the multivariate analysis. Neither was there any significant difference in sociodemographic (education and ethnicity), obstetric (parity, ANC check-up and delivery preparation) and neonatal characteristics (preterm birth and sex). Complications during pregnancy were, however, three times more common among misclassified than among true antepartum stillbirths.

\section{Methodological consideration}

The study conducted rigorous surveillance to collect data on the demographic, obstetric and neonatal characteristics of the women who participated in the study. One of the major strengths of this study is inclusion of large sample from 12 public hospitals located in different geographical locations in Nepal. Further, another strength of this study is inclusion of all in-born babies and stillbirths.

However, we acknowledge limitations in the study. First, there was an independent data collection team stay 
Table 2 Multivariate analysis on the risk factor for misclassification

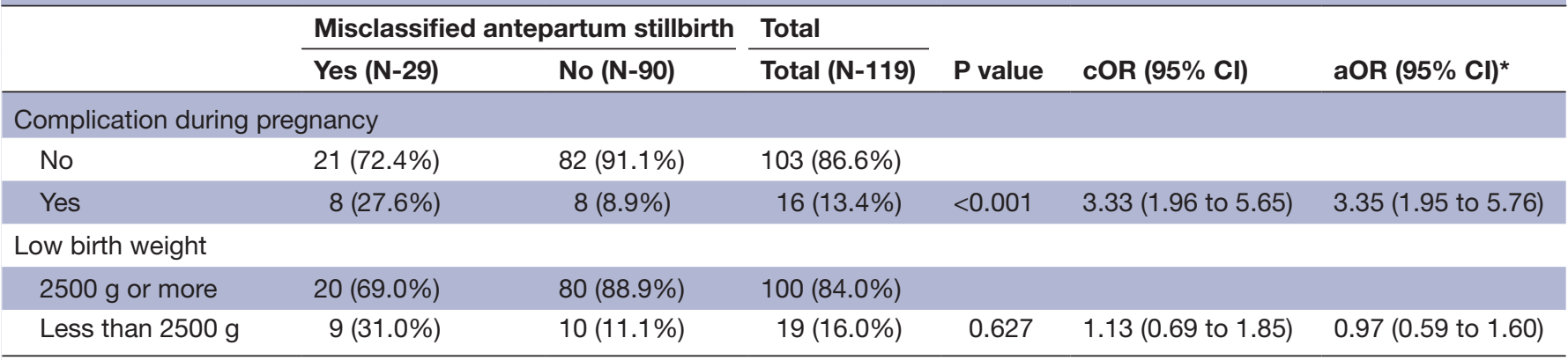

${ }^{*}$ Adjusted for complication during pregnancy and low birth weight.

aOR, adjusted OR; cOR, crude OR.

and recorded the clinical events from the case notes. The presence of an independent team might have caused changes in routine care and recording as a Hawthrone effect. ${ }^{20}$ Second, the record of clinical events and birth outcomes was assessed from the patient case notes and data could have been missing. Third, we conducted an interview at the time of discharge to gather information regarding sociodemographic and antenatal care. Women's responses to some of the questions, such as education and antenatal care, might not be reliable and result in biases. In addition, we were not able to interview all mothers enrolled in the study, which might have resulted in missing information. Fourth, we did not conduct an in-depth review of the underlying cause of misclassification and the value of the birth outcome. Fifth, the quality of the fetal heart rate monitoring might have been variable. Sixth, the quality of fetal heart rate measurement at admission and before birth might not have been of highest standard as evident from figure 3, wherein among the 136 women who had absent FHS at admission and before birth, 129 of them gave birth to a live born baby. Finally, since, the number of misclassified antepartum stillbirth was not adequate enough to show the association between low birth weight and misclassification there might be a type 2 error occurring with respect to the lack of association.

There are different reasons for a clinical staff for misclassification of antepartum stillbirth. First, lack of knowledge among clinical staffs on the standard definition of antepartum stillbirth. Second, clinical staff might misclassify intrapartum stillbirth as antepartum stillbirth to avoid the accountability of poor intrapartum care. Third, the clinical staff might not value identifying and recording true antepartum stillbirth.

Measurement of health process and outcome of women and children has social, political and contextual nature. ${ }^{21}$ Socially, measurement of any service is used by the general public to assess the quality of care. Politicians and policy maker may also use the same data measurement to showcases the change in service delivery. In the hospital context, it is used for quality improvement. Prioritising any measurement outcome of maternal and neonatal health in a hospital or health system depends on the governance of data and information by the leadership, health worker and healthcare recipient. A review of data quality in the National Health Service showed a lack of participation in the management and use of data is one of the key issues to resolve. ${ }^{22}$ The audit report cites that 'the perception that hospital episode statistics cannot support the needs of the individual health workers results in mistrust and disinterest. This leads to a poor data generation and recording by health workers. This in turn leads to under-development of such data from a clinical perspective, and the cycle continues'.

The other critical underlying factor for poor data quality is lack of understanding among frontline staff of the reasons for, and benefits of, the information they are collecting. The information generated is not client centred for improving care. ${ }^{23}$

A randomised study in National Health Service to evaluate participation of physicians in improvement of data validity and use showed that the current measurement system on episode statistics, that is, mortality, is not fit to monitor the performance of individual physicians. ${ }^{24}$

An observational cross-sectional study was conducted in three hospitals in Afghanistan to validate the accuracy of health events and outcome in the patient case note. For the indicators of asphyxia, postpartum hemorrhage (PPH) and laceration, for which sensitivity was low, failing to accurately identify cases may have a detrimental effect on clinical decision making. This could potentially lead to an increase in the risk of adverse outcomes for resuscitated neonates or mothers because they miss follow-up observation and care indicated by these diagnoses. Specificity and proportion of cases correctly classified were generally higher in records taken from registers compared with those take from medical charts, while sensitivity was lower in the registers. This could be because the registers are generally used to record lowfrequency events and clinicians may think it is more important to capture the occurrence of those events than their absence. ${ }^{25}$

Another study in Afghanistan showed the recording of information on obstetric events and outcomes in caesarean section was poor. ${ }^{26} \mathrm{~A}$ study conducted by Kim and colleagues on the quality of caesarean section 
documentation showed poor recording in the case notes which also lead to misclassification of clinical events, such as FHS and birth outcome including stillbirths. ${ }^{27}$

Our Nepal study from the same cohort has found that more than $45 \%$ of the intrapartum stillbirth were potentially misclassified who would have been a liveborn if resuscitated at birth. ${ }^{28}$

\section{CONCLUSION}

Almost 25\% of recorded antepartum stillbirths in public hospitals in Nepal were misclassified antepartum stillbirth. Women who had complications during pregnancy were at increased risk of being misclassified antepartum stillbirth. Accurate classification of the timing of stillbirth is critical as strategies to prevent these outcomes would vary significantly. Improving fetal heart rate monitoring and its correct recording is crucial to reduce misclassification. With 10 years remaining for countries to report on their progress made in stillbirth rate reduction, highquality routine information of antepartum stillbirth is an urgent need to track progress.

Acknowledgements The study group would like to thank Dr Avinash K Sunny and Pragya Gautam for the review and input in the paper. We would like to acknowledge all the data collectors who collected the data from the hospitals.

Contributors AKC conceptualised the study. RG and AKC made the first draft of the manuscript. $\mathrm{HL}$ reviewed the first draft. SB and $\mathrm{HZ}$ reviewed the second draft. All authors read and approved of the final version.

Funding Einhorn Family Foundation, Swedish Research Council (VR) and Laerdal Foundation for Acute Medicine, Norway support the funding for the study.

Competing interests None declared.

Patient consent for publication Not required.

Ethics approval Ethical approval was provided by the ethical review board of Nepal Health Research Council (ref-247/2017).

Provenance and peer review Not commissioned; externally peer reviewed.

Data availability statement Data are available upon reasonable request.

Open access This is an open access article distributed in accordance with the Creative Commons Attribution Non Commercial (CC BY-NC 4.0) license, which permits others to distribute, remix, adapt, build upon this work non-commercially, and license their derivative works on different terms, provided the original work is properly cited, appropriate credit is given, any changes made indicated, and the use is non-commercial. See: http://creativecommons.org/licenses/by-nc/4.0/.

ORCID iD

Ashish KC http://orcid.org/0000-0002-0541-4486

\section{REFERENCES}

1 Lawn JE, Blencowe $\mathrm{H}$, Waiswa $\mathrm{P}$, et al. Stillbirths: rates, risk factors, and acceleration towards 2030. Lancet 2016;387:587-603.

2 Blencowe H, Cousens S, Jassir FB, et al. National, regional, and worldwide estimates of stillbirth rates in 2015, with trends from 2000: a systematic analysis. Lancet Glob Health 2016;4:e98-108.

3 World Health Organization. Every newborn an action plan to end preventable deaths. Geneva: WHO, 2014.

4 Lawn JE, Blencowe H, Oza S, et al. Every newborn: progress, priorities, and potential beyond survival. Lancet 2014;384:189-205.
5 Moxon SG, Ruysen H, Kerber KJ, et al. Count every newborn; a measurement improvement roadmap for coverage data. $B M C$ Pregnancy Childbirth 2015;15(Suppl 2):S8.

6 Day LT, Ruysen H, Gordeev VS, et al. 'Every Newborn-BIRTH' protocol: observational study validating indicators for coverage and quality of maternal and newborn health care in Bangladesh, Nepal and Tanzania. J Glob Health 2019;9:010902.

7 Lawn JE, Blencowe H, Pattinson R, et al. Stillbirths: where? when? why? how to make the data count? Lancet 2011;377:1448-63.

8 Pattinson R, Kerber K, Buchmann E, et al. Stillbirths: how can health systems deliver for mothers and babies? Lancet 2011;377:1610-23.

9 World Health Organization U. Every newborn action plan progress report 2018. Geneva, 2019.

10 Marchant T, Bhutta ZA, Black R, et al. Advancing measurement and monitoring of reproductive, maternal, newborn and child health and nutrition: global and country perspectives. BMJ Glob Health 2019;4:e001512.

11 Boerma T, Requejo J, Victora CG, et al. Countdown to 2030: tracking progress towards universal coverage for reproductive, maternal, newborn, and child health. Lancet 2018:391:1538-48.

12 Amouzou A, Leslie HH, Ram M, et al. Advances in the measurement of coverage for $\mathrm{RMNCH}$ and nutrition: from contact to effective coverage. BMJ Glob Health 2019;4:e001297.

13 Kc A, Bergström A, Chaulagain D, et al. Scaling up quality improvement intervention for perinatal care in Nepal (NePeriQIP); study protocol of a cluster randomised trial. BMJ Glob Health 2017;2:e000497.

14 von Elm E, Altman DG, Egger M, et al. The strengthening the reporting of observational studies in epidemiology (STROBE) statement: guidelines for reporting observational studies. Int J Surg 2014;12:1495-9.

$15 \mathrm{Kc} \mathrm{A}$, Ewald U, Basnet O, et al. Effect of a scaled-up neonata resuscitation quality improvement package on intrapartum-related mortality in Nepal: a stepped-wedge cluster randomized controlled trial. PLoS Med 2019;16:e1002900.

16 WHO, UNICEF, UNFPA, AMDD. Monitoring emergency obstetric care, a Handbook. Geneva, 2009.

17 Gabrysch S, Zanger P, Campbell OMR. Emergency obstetric care availability: a critical assessment of the current indicator. Trop Med Int Health 2012;17:2-8.

18 World Health Organization. Managing complications in pregnancy and childbirth: a guide for midwives and doctors. Geneva, 2000.

19 Subedi M. Caste system: theories and practices in Nepal. Himalayan J Sociol Anthropol 2010;4:134-59.

20 Paradis E, Sutkin G. Beyond a good story: from Hawthorne effect to reactivity in health professions education research. Med Educ 2017;51:31-9.

21 George A, LeFevre AE, Jacobs T, et al. Lenses and levels: the why, what and how of measuring health system drivers of women's, children's and adolescents' health with a governance focus. BMJ Glob Health 2019:4:e001316.

22 Croft GP, Williams JG. The RCP information laboratory (iLab): breaking the cycle of poor data quality. Clin Med (Lond) 2005:5:47-9.

23 Audit Commission. Data remember: improving the quality of patient based information in the NHS. London: Audit Commission, 2002.

24 Croft GP, Williams JG, Mann RY, et al. Can Hospital episode statistics support appraisal and revalidation? Randomised study of physician attitudes. Clin Med (Lond) 2007;7:332-8.

25 Broughton El, Ikram AN, Sahak I. How accurate are medical record data in Afghanistan's maternal health facilities? An observational validity study. BMJ Open 2013;3:e002554.

26 Kandasamy T, Merialdi M, Guidotti RJ, et al. Cesarean delivery surveillance system at a maternity hospital in Kabul, Afghanistan. Int J Gynaecol Obstet 2009;104:14-17.

27 Kim Y-M, Tappis H, Zainullah P, et al. Quality of caesarean delivery services and documentation in first-line referral facilities in Afghanistan: a chart review. BMC Pregnancy Childbirth 2012:12:14.

28 Kc A, Berkelhamer S, Gurung R, et al. The burden of and factors associated with misclassification of intrapartum stillbirth: evidence from a large scale multicentric observational study. Acta Obstet Gynecol Scand 2019. doi:10.1111/aogs.13746. [Epub ahead of print: 10 Oct 2019]. 